\title{
Relationship between freight accessibility and logistics employment in US counties
}

Frank P. van den Heuvel, Liliana Rivera, Karel H. van Donselaar, Ad de Jong, Yossi Sheffi, Peter W. de Langen, and Jan C. Fransoo

This paper analyzes the relationship between freight accessibility and logistics employment in the US. It develops an accessibility measure relevant for logistics companies based on a gravity model. This allows for an analysis of the accessibility of US counties focusing on four different modes of transportation: road, rail, air, and maritime. Using a Partial Least Squares model, these four different freight accessibility measures are combined into two constructs, continental and intercontinental freight accessibility, and related to logistics employment. Results show that highly accessible counties attract more logistics employment than other counties. The analyses show that it is very important to control for the effect of the county population on both freight accessibility and logistics employment. While county population explains the most variation in the logistics employment per county, there is a significant relationship between freight accessibility and logistics employment, when controlling for this effect.

Keywords: Accessibility, Freight transport, Logistics employment

\section{Introduction}

One of the key factors to a region's economic performance is a reliable and efficient transportation infrastructure. "A well-developed transportation system provides adequate access to the region, which in turn is a necessary condition for the efficient operation of the manufacturing, retail, labor, and housing markets" (Ozbay et al., 2006, p.3). The accessibility of a location is, naturally, an important factor for the location decision of logistics companies (such as third party logistics service providers, warehouses, motor carriers, and the logistics/distribution operations of retailers, distributors and manufacturers). Better accessibility results in lower transportation costs and a shorter time to the market (Limão and Venables, 2001), which have a direct impact on the cost and service level that logistics operations enjoy. Therefore, logistics employment is expected to be concentrated in areas that are highly accessible. Hence, it is not surprising that improvements to the road network significantly affect the location of agglomerations of logistics firms (Taniguchi et al., 1999), that logistics clusters in the US are primarily developed close to major airports and seaports and in central areas such as Chicago, Kansas City and Dallas (Rivera and Sheffi, 2012), or that logistics establishments in the Netherlands relocate relatively often in areas with intermodal terminals (Van den Heuvel et al., 2013). In this paper, we analyze whether there is a general relation between freight accessibility and logistics employment. This topic may be especially relevant given Hesse's (2008) argument that logistics investments may accelerate economic development of areas. This argument is also advanced by Sheffi (2012), who demonstrates that logistics clusters attract manufacturing subclusters. Several studies have found that accessibility is an important factor for urbanization (population and employment growth, see e.g. Jiwattanakulpaisarn et al., 2010, and Song et al., 2012). However, the relationship between freight accessibility and logistics employment has hardly been studied. Such an analysis requires a measure of freight accessibility. Although freight accessibility is important for location decisions of companies (Porter and Rivkin, 2012), limited efforts have been put 
in developing freight accessibility measures ${ }^{1}$. This paper addresses these gaps; we develop a freight accessibility index and analyze the relationship between freight accessibility and logistics employment.

The remainder of this paper is structured as follows. Section 2 presents an overview of the relevant literature on the relationship between accessibility and employment, while Section 3 reviews the academic literature on accessibility measures. Section 4 presents an accessibility measure especially developed for freight transport. Using data at the county level in the US, Section 5 presents the analysis into the relation between freight accessibility and logistics employment per county, based on a Partial Least Squares model. Finally, Section 6 concludes the paper and discusses options for further research.

\section{Relationship between accessibility and employment}

The relationship between transport infrastructure investments (not specifically accessibility) and spatial development has been widely studied (e.g., Rietveld, 1994, Berechman, 1994, Berechman et al., 2006, and Ribeiro et al. 2010). These studies show that transport infrastructure investments can both have positive (increased population or gross product) and negative economic impacts (degradation of the region, because firms and residents can move away from the region more easily). Transport infrastructure investments positively influence an area's economic growth if three conditions are met: it increases accessibility within a region, transport is a relevant input for the processes of the firms in the area, and the infrastructure does not generate significant negative environmental externalities (Berechman, 1994).

Scholars have also analysed the relationship between accessibility and growth of jobs and population. Weisbrod et al. (1993) found that the impact of airport-induced job growth on land use in the vicinity of airports is substantial. Areas within four miles of airports added jobs two to five times faster than the overall suburban ring in which the airport is located. Most of the employment was concentrated around the airport or along a major access corridor within fifteen minutes of the airport. In addition, Allen et al. (1993) look at the effect of accessibility on different types of areas. He concludes that accessibility has a significant effect on employment growth rates in central business districts and areas outside the central city; no significant effect was found in the rest of the central city areas. Thompson and Taniguchi (2001) conclude that the construction of transportation infrastructure (increasing accessibility) leads to employment growth and lower consumer prices of commodities at the city level. The effects at the state level are addressed by Jiwattanakulpaisarn et al. (2010), who conclude that increased accessibility is a determinant of state employment growth in the service sector. Next to employment, the effect of accessibility on labor supply has also been analyzed thoroughly (see e.g. Hansen, 1959; Banister and Berechman, 2000; Berechman and Paaswell, 2001; Ozbay et al., 2006; Du and Mulley, 2007). A common approach is to assume that individuals allocate their total daily hours between work and non-work activities. Hence, reduced travel time will result in more time available for both work and leisure time activities. Given assumptions on work/leisure time substitution as well as on the income effect from reduced travel times and costs, improved accessibility has a positive effect on the amount of labor that individuals are willing to supply (Ozbay et al., 2006).

\footnotetext{
${ }^{1}$ This lack of research is in contrast with passenger accessibility. This may be explained by the fact that passenger cars account for $89.8 \%$ of the vehicle-miles on US roads, while trucks only account for $9.1 \%$ of the vehicle-miles traveled. The rest are buses and motorcycles that represent 1.1\%. (US Department of Transportation, 2011b).
} 
Regarding population, Chi (2010) shows a positive effect of highway expansion on population change in rural and suburban areas on the lowest geographical scale in the US, the minor-civil division level. In urban areas, there is no effect. In addition, Chi (2012) shows that airport accessibility and highway improvement promote population growth in rural areas. In suburban areas, airport accessibility promotes population growth, while highway accessibility facilitates migration of population out of the area. In urban areas, highways and airports have no significant effect on population growth. Chi $(2010,2012)$ explains these outcomes by the fact that infrastructure does not create a comparative advantage when none exists; it just facilitates flows of people (and freight) from one location to the other. Furthermore Chi $(2010,2012)$ argues that in urban areas, infrastructure development reaches maturity, meaning that extra investments do not result in growth or development of the area.

Finally, the importance of road transport infrastructure in the location decision of firms has been studied. This importance varies with various firm characteristics. Leitham et al. (2000) show that for newly built industrial premises in the UK, firms from within the UK indicate a higher importance of road links than firms from outside the UK. Similarly, for location decisions made by foreign logistics firms in China, road transport infrastructure is more important for the location decision for headquarters than for logistics establishments. Furthermore, new firms were more attracted by road transport infrastructure than mature firms (Hong, 2007).

None of the aforementioned works specifically analyze the relationship between freight accessibility and logistics employment. In the logistics industry accessibility is an important location factor because better accessibility translates to lower transportation costs and shorter time to markets (Limão and Venables, 2001). Hence, areas with better accessibility are expected to attract logistics firms, leading to more logistics employment. This paper investigates the hypothesis that areas with higher accessibility have higher levels of logistics employment. This study expands Bowen's (2008) study, in which he correlated the number and growth of warehouse establishments per US county to accessibility. Based on an analysis in 143 counties part of 50 randomly selected Metropolitan Statistical Areas, Bowen (2008) found a high correlation between the number of warehouse establishments in a county and the county's air and highway accessibility, in 1998 and 2005. He also found a high correlation between these accessibility measures and the growth in the number of warehouse establishments in the period 1998-2005. Based on the outcomes of Páez (2004), who found strong multivariate relationships, we will not only analyze bivariate relationships, but also use structural equation models to analyze multivariate relationships. Furthermore, in line with previous studies that find differences between urban and rural areas (e.g., Chi, 2010, 2012), we differentiate between metropolitan and non-metropolitan areas, to be able to analyze differences of the relationship between freight accessibility and logistics employment in these types of areas.

\section{Accessibility measures}

There are many accessibility measures available (e.g., Ingram, 1971; Morris et al., 1978; Handy and Niemeier, 1997; El-Geneidy and Levinson, 2006; Bowen, 2008). Most are specifically developed for passenger transport. Only a few authors explicitly analyzed freight accessibility. Thomas et al. (2003) analyze freight accessibility in Belgium based on three different transportation modes: road, rail, and waterways. These authors use gravity-based measures weighting the nodes of the transportation system by population and economic activity. They conclude that there is a positive relation between the transportation infrastructure and population, but economic activities are less associated with the transportation system than with the population.

Lim and Thill (2008) and Thill and Lim (2010) also analyzed highway freight accessibility by means of a gravity-based measure. These authors weight the shipping costs by a measure of economic 
opportunity that is designed as a combination of population, employment, final demand, and intermediate demands of manufactured goods. They find that the implementation of intermodal networks reduces the gap of accessibility among peripheral and central regions in the US.

To analyze the relationship between accessibility and the number of warehouse establishments, Bowen (2008) defined four different accessibility measures, based on different modes of transportation. Air accessibility was measured by an ordinal value based on the distance to the nearest airport and the air-cargo tonnage handled at that airport. Similarly, maritime accessibility was measured with an ordinal value on indices based on the distance to the nearest container port and the number of containers handled at that port. Road and rail accessibility were measured with densitybased measures, as they measure accessibility by the density of (rail)roads per region. Road accessibility was defined as the total centerline length of the interstate and other elements of the national highway system within a county divided by the county's area. Similarly, rail accessibility was defined as the length of all Class I railroads within a county divided by the county's area.

This paper extends and improves this analysis. Like Bowen, we define accessibility measures based on four different modes of transportation. Bowen's measures are relatively easy to calculate. The major criticism on the density-based measures is that they calculate accessibility values per county independent of the accessibility of adjacent counties. In our view, (freight) accessibility is also determined by (rail)roads in adjacent counties. We will use gravity-based accessibility measures (see e.g. Handy and Niemeier, 1997; Thomas et al., 2003; El-Geneidy and Levinson, 2006) that do consider adjacent counties. These measures are based on the following definition of accessibility (Hansen, 1959, p. 73) "accessibility at point 1 to a particular type of activity at area 2 ... is directly proportional to the size of the activity at area 2 ... and inversely proportional to some function of the distance separating point 1 from area 2. The total accessibility [to the type of activity of interest] at point 1 is the summation of the accessibility to each of the individual areas around point 1". Gravitybased measures weight opportunities, usually the quantity of an activity in a certain area, by impedance, generally a function of distance, travel time, or travel costs.

Two other commonly used accessibility measures are the cumulative opportunity and random utility measures (Handy and Niemeier, 1997, Páez et al. 2012). Cumulative opportunity measures count the number of opportunities that can be reached within a predetermined travel time or distance. Gravitybased measures can be formulated as cumulative opportunity measures with the impedance function equal to one if within the predetermined distance/time and zero otherwise (Koenig, 1980; Handy and Niemeier, 1997). The major disadvantage of the cumulative opportunity measures is the arbitrary cutoff value used for the predetermined travel time or distance. For example, if the airports within 70 kilometers are counted, an airport at 68 kilometers is taken into account, while an airport at 72 kilometers is not. This disadvantage can be overcome by making use of fuzzy decision making, which is based on boundaries that are not sharply defined (e.g., Bellman and Zadeh, 1970). As this method also results in fuzzy outcomes, we prefer to use gravity-based accessibility measures, which use travel times to weight the opportunities in other areas, instead of crisp cut-off values.

Random utility measures use preferences of individual travelers to estimate the utility of certain choices (for example, mode choice in travel to work). A metric that takes into account the contribution of all such utilities for a set of individuals in a location is used as an accessibility measure. A common example is the multinomial logit model which uses a maximum likelihood estimator to calculate the parameter of the utility of each alternative, given data about the attributes of that and competing alternatives. The denominator of the multinomial logit model can be used as an accessibility measure, since it is a scalar summary of the expected utility of a set of travel alternatives (Ben-Akiva and Lerman, 1985). These measures were originally developed to model individuals' travel choices and 
reflect the individual's attributes. Utility-based measures use observable temporal and spatial transportation components of specific choices in person-specific choice sets (Handy and Niemeier, 1997). In the case of freight transport, these person (in this case company) specific choices can be approximated by a function of activity and distance. The result essentially is a monotone increasing function of the gravity-based measure (Geurs and Van Wee, 2004).

Finally, due to the increased computational power of geographical information systems (GIS), spacetime accessibility measures have been proposed that explicitly acknowledge an individual's travel behavior (Miller, 1999; Neutens et al., 2010). These measures are specifically focused on the participation of individual people in certain activities, while the accessibility measures described above assume that all alternatives are available for all individuals. We will not make use of this type of accessibility measures, because of two reasons. First, our analysis is place-based, meaning that we want to measure the accessibility of a certain location, not of specific individuals. Our goal is to compare the accessibility to the amount of logistics employment per location. Second, we want to measure accessibility such that it is relevant for logistics firms, not individual people.

\section{Freight accessibility measures for logistics establishments in the US}

This section describes the accessibility measures in detail. For comparison, Appendix A presents the measures used by Bowen (2008). The modes of transportation that are included are road, air, maritime, and rail transport.

\subsection{Gravity-based accessibility measures}

As described in Section 3, gravity-based measures use the distance or travel time to other areas and the activity in these other areas to measure accessibility. We use the following standardized measure $A_{g, i}$ for all US counties $i \in\{1, \ldots, l\}$ :

$$
A_{g, i}=\frac{a_{g, i}}{\frac{1}{l} \sum_{j \in l} a_{g, j}} \text { with } a_{g, i}=\sum_{j \in l} w_{j} \cdot f\left(t_{i, j}\right)
$$

with:

$A_{g, i}=$ Accessibility (gravity-based) of county $i$,

$w_{j}=$ Weight representing the importance of location $j$,

$t_{i, j}=$ Measure of separation between counties $i$ and $j$ (generally being distance or time),

$f\left(t_{i, j}\right)=$ Impedance function,

$I=$ Number of US counties $(=3109)$.

Gravity-based measures explicitly take into account that accessibility not only is the ease with which other areas can be reached, but also the importance of these areas. This is determined by the weight $w_{j}$. With various ways of measuring the importance of locations and of determining the separation (impedance) between counties, several gravity-based measures for freight accessibility are defined.

\subsection{Road accessibility}

For the road accessibility measure, $t_{i, j}$ is defined as the travel time in minutes between the center points of counties $i$ and $j^{2}$. The following impedance function is used:

\footnotetext{
2 These travel times were determined using the US detailed streets map from Tele Atlas North America 2007, available from ESRI (www.esri.com, accessed December 2012).
} 
$f\left(t_{i, j}\right)= \begin{cases}1 & \text { if } i=j \\ b \cdot e^{-c \cdot t_{i, j}} & \text { if } i \neq j \text { and } t \leq t_{\max } \\ 0 & \text { otherwise }\end{cases}$

with $t_{\max }=720$ (see below), $b=1.0000$ and $c=0.0166$.

The impedance function is based on data describing the primary range of operations of US trucks (US Census, 2002). As these data present the number of truck trips for five different range classes, these indicate what weight should be given to activities within a certain travel time. A negative exponential function fits these data best. Figure 1 presents the function used in this paper. ${ }^{3}$ Because $f\left(t_{i, j}\right)$ approaches zero as $t_{i, j}$ increases, a maximum $t_{\max }$ is used, obviating the need for a complete matrix of travel times between all 3109 US counties.

The importance of county $j$ determines how much weight it gets in determining the accessibility of county $i$. To measure road accessibility per county, importance is measured in two different ways:

- $A_{g}$ (road:distribution) uses retail sales (US Census, 2007a) in county $j$, as many logistics companies focus on the distribution to retail outlets.

- $A_{g}$ (road:manufacturing) uses the value of shipments of all manufacturing establishments (US Census, 2007a) in county $j$. This represents locations were raw material and parts are transported to. For these data, the US Census does not disclose about 15 percent of the county values, only omitting the counties where manufacturing employment is less than 500 people.

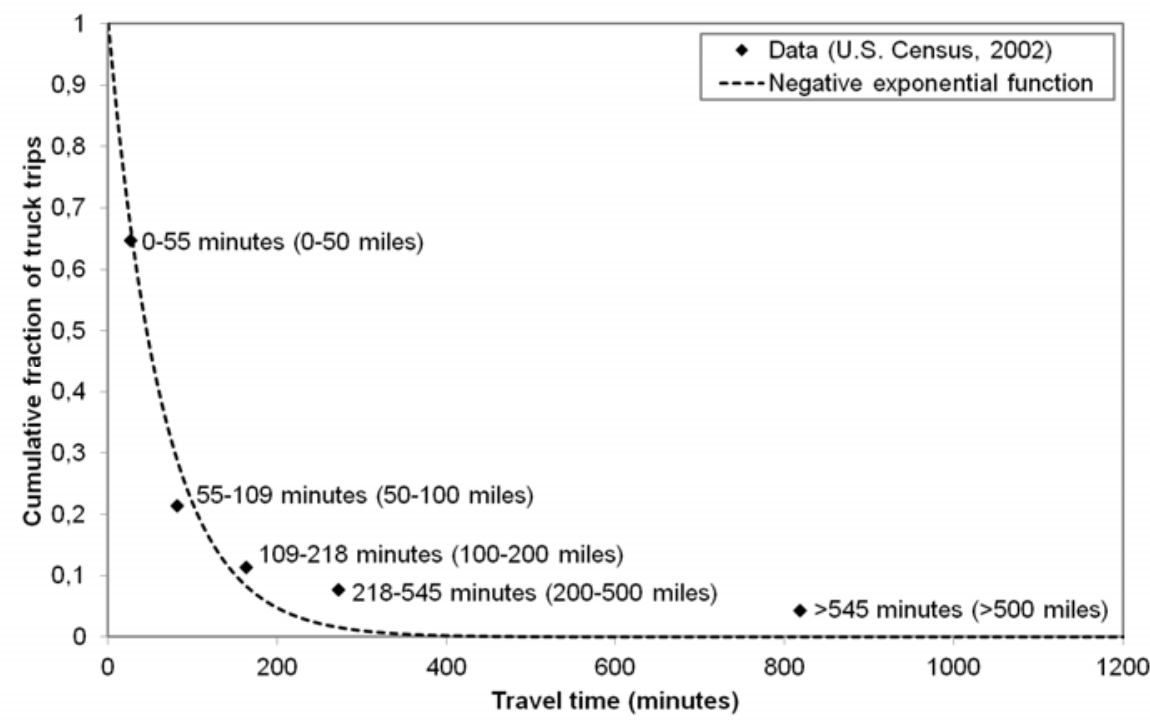

Figure 1: Impedance function used, based on primary range of operations of US trucks (US Census, 2002) and an average speed of 55 miles per hour.

\subsection{Air, maritime, and rail accessibility}

Similar to road accessibility, air, maritime, and rail accessibility of US counties can be measured using the travel times between counties by air, sea, and rail, respectively. However, while road travel times

\footnotetext{
${ }^{3}$ Parameters were determined by fitting the best function on the data, with CurveExpert Professional 1.3 (www.curveexpert.net, accessed December 2012). This software uses the Levenberg-Marquardt method to solve nonlinear regressions, which combines the steepest-descent method and a Taylor series based method (Levenberg, 1944; Marquardt, 1963).
} 
can be calculated relatively easily, this is not the case for travel times using other transport modes. These times depend on the services provided on these networks. The road network can be accessed by everybody with a motor vehicle on every moment of the day. The air, maritime, and rail transport networks can only be accessed at specific locations at specific moments in time, determined by the services provided by the operators on these networks. Consequently, air, maritime, and rail accessibility are measured based on the travel times by road needed to access these networks, i.e. $t_{i, j}$ is the travel time by road from the center point of county $i$ to the center point of county $j$, that has an airport, seaport, or rail terminal.

Matisziw and Grubesic (2010) show for commercial air passenger traffic that having access to an airport is not the same as having good accessibility to the commercial air transport system. Although this difference is expected to be smaller in freight transportation, we control for this by not only using the access to a(n) (air)port, but also the size of the (air)port, measured by the cargo handled, which is used as a proxy for the connectivity or importance of the (air)port. Air accessibility is defined as $A_{g}$ (air). The weight $w_{j}$ is defined based on the total landed weight of the top 25 US freight airports, which is the certificated maximum gross landed weight of the aircraft as specified by the aircraft manufacturers in county $j$ (US Department of Transportation, 2010). These airports account for about $75 \%$ of the landed weight of all US freight airports. ${ }^{4}$ Similarly, maritime accessibility is defined as $A_{g}$ (maritime). The total loaded container traffic (in TEU) of the top 25 US seaports (US Army Corps of Engineers, 2010) in county $j$ is used to approach the importance of the seaport in that county $\left(w_{j}\right)$. These top 25 ports account for about $98 \%$ of the loaded container traffic of all US seaports.

While many operators provide air and maritime transportation services, the freight rail network in the US is mainly operated by seven Class I freight railroad companies. ${ }^{5}$ Data about the cargo handled at the terminals are not available. Hence, rail accessibility, $A_{g}($ rail), uses the number of intermodal rail terminals from different Class I freight railroads (US Department of Transportation, 2011c) in county j as a proxy for the size of activity or importance of the rail hubs in the county $\left(w_{j}\right)$. The importance of the area is higher the higher the number of railroad companies that have an intermodal terminal located in the area, as shippers can reach more locations by rail and have more bargaining power.

\section{Accessibility of US counties and the relation to logistics}

This section applies the accessibility measures described above on a county level in the US and relates this to the logistics employment per county.

\subsection{Material used}

Logistics employment is defined as the paid employees of the establishments performing activities in the following sectors: freight transport, cargo handling, storage and warehousing, and other supporting transport activities. Appendix B presents a list of NAICS codes used to identify logistics establishments. We use logistics employment instead of logistics establishments, as this better approximates the size of the logistics sector per region and hence, the need for good accessibility.

\footnotetext{
${ }^{4}$ Analyses were also conducted on the top 30 and top 35 US freight airports, accounting for $79 \%$ and $81 \%$, respectively, of the landed weight of all 124 US freight airports. Results were similar to the ones presented for the top 25 US freight airports.

${ }^{5}$ Railroad class is determined based on revenue, with "Class I" implying the largest revenue (at least $~ \$ 400$ million annually in 2010). The five US Class I freight railroads include the Burlington Northern and Sante Fe (BNSF), CSX Transportation (CSX), Kansas City Southern (KCS), Norfolk Southern (NS), and Union Pacific (UP). The two large Class I Canadian Railroads, Canadian National (CN) and Canadian Pacific (CP), operate both in the US and Canada.
} 
Data are gathered from the 2007 County Business Patterns (US Census, 2007a,b). All data used are from 2007, as these are the most recent US Census Economic Survey data available. Since data are gathered on a six-digit NAICS code level, not all employment data are disclosed by the US Census. In the data, $29 \%$ of the counties do not have logistics employment, even though there are logistics establishments. Hence, in counties where data are not disclosed, logistics employment was estimated based on the number of establishments within a particular employment class and the average size of a logistics establishment in that class. Based on these estimates, the average logistics employment per county equals 1029 people (with a median of 149) and the average number of logistic establishments per county is 58 (with a median of 21). Figure 2 depicts the logistics employment per county.

Previous studies have shown that there is a significant relation between the accessibility and population of a region (Thomas et al. 2003; Zhenbo et al., 2011; Chi, 2012; Fan et al. 2012). In addition, population is strongly related to employment (De Graaff et al., 2012a). This also applies to the distribution sector (De Graaff et al., 2012b). Populated centers offer availability of labor and proximity to consumers for logistics companies. Hence, we include this variable in the analysis. We acknowledge the shortcoming that population is in general highly correlated with employment; finding a relation between population and logistics employment is somewhat trivial. Yet, by controlling for this relation in a multivariate analysis we can determine whether there is a significant relationship between freight accessibility and logistics employment. The population of adjacent counties is considered as well, as Jiwattanakulpaisarn et al. (2010) showed that employment gains from improvements in interstate highways may negatively affect employment in other states due to negative spillovers, thus shifting service jobs away from other states. This effect may also be relevant on a country-level.

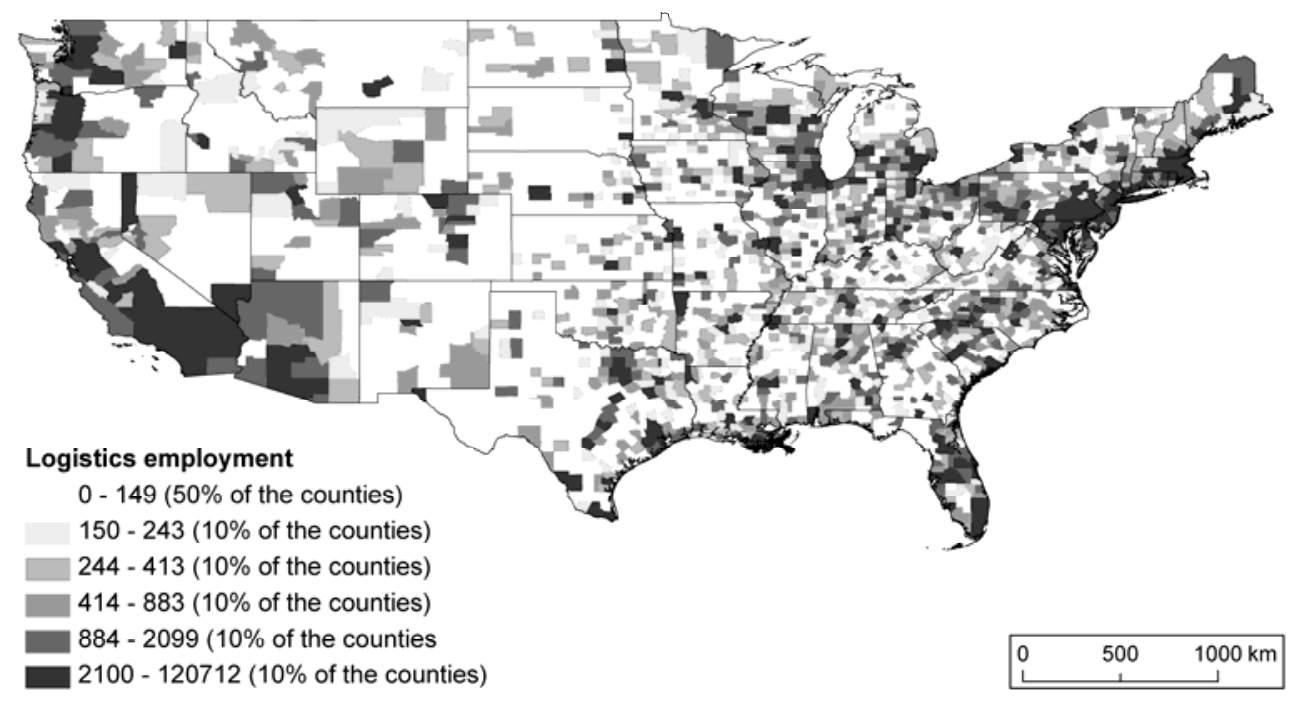

Figure 2: Top 50\% counties based on logistics employment.

The average population per county is 96,372 people, while the median is 25,605 . Based on this relatively large difference and the differences previously found between urban and rural areas (Chi, 2010, 2012), we differentiate between counties in Metropolitan Statistical Areas (MSAs; 1,088 counties) and counties not in these areas (2,021 counties). MSAs are geographic entities defined by the Office of Management and Budget (OMB) for use by Federal statistical agencies. An MSA contains a core urban area of 50,000 or more people. Each MSA consists of one or more counties and includes the core urban area, as well as any adjacent counties that have a high degree of social 
and economic integration with the urban core (measured by commuting to work, see US Census 2012b). Table 1 presents descriptive statistics for all counties, metropolitan area counties and nonmetropolitan area counties.

Table 1: Descriptive statistics of US counties.

\begin{tabular}{|c|c|c|c|}
\hline & & Population (\#) & \begin{tabular}{|c|} 
Logistics \\
employment (\#)
\end{tabular} \\
\hline \multirow[t]{4}{*}{ Total } & Sum & $299,620,766$ & $3,199,866$ \\
\hline & Median & 25,605 & 149 \\
\hline & Average & 96,372 & 1,029 \\
\hline & St. Dev. & 309,917 & 3,951 \\
\hline \multirow[t]{4}{*}{ Metropolitan } & Sum & $250,519,926$ & $2,725,681$ \\
\hline & Median & 96,508 & 755 \\
\hline & Average & 230,257 & 2,505 \\
\hline & St. Dev. & 495,954 & 6,398 \\
\hline \multirow[t]{4}{*}{ Non-metropolitan } & Sum & $49,100,840$ & 474,185 \\
\hline & Median & 16,598 & 89 \\
\hline & Average & 24,295 & 235 \\
\hline & St. Dev. & 23,835 & 437 \\
\hline
\end{tabular}

Table 2 shows the correlations between the accessibility measures described in Section 3 and the logistics employment per US county. All accessibility measures have a significant relation with logistics employment. In addition, population has a very high correlation with logistics employment, especially in the metropolitan area counties, and also a significant correlation with all accessibility measures. While Bowen (2008) only uses correlations to conclude that there is a relation between the number of warehouse establishments and accessibility per county, Table 2 shows that in most cases the correlation between accessibility and population is higher than the correlation between accessibility and logistics employment. Hence, to test whether the relationship between logistics employment and freight accessibility is not spurious, other techniques have to be used that are able to control for the effect of population.

Table 2: Pearson correlation coefficients.

a. All counties $(N=3109)$.

\begin{tabular}{|c|c|c|c|}
\hline & (1) & $(2) \quad(3)$ & $\begin{array}{llll}(4) & (5) & (6) & (7)\end{array}$ \\
\hline (1)Logistics employment & $>$ & $0.909^{*} 0.434^{\star}$ & $0.449^{*} 0.451^{*} 0.344^{*} 0.552^{*} 0.442^{*}$ \\
\hline (2) Population & & $0.530^{*}$ & $0.531^{*} 0.482^{*} 0.309^{*} 0.628^{*} 0.436^{*}$ \\
\hline (3) Population in adjacent counties & & & $0.591^{*} 0.522^{*} 0.278^{*} 0.412^{*} 0.453^{*}$ \\
\hline (4) $\mathrm{A}_{g}$ (road:distribution) & & & $0.844^{*} 0.478^{*} 0.617^{*} 0.707^{*}$ \\
\hline (5) $A_{g}$ (road:manufacturing) & & & * $0.761^{*}$ \\
\hline (6) $A_{g}($ air $)$ & & & $0.335^{\star} 0.495^{\star}$ \\
\hline (7) $A_{g}$ (maritime) & & & $0.330^{*}$ \\
\hline (8) $A_{g}$ (rail) & & & \\
\hline
\end{tabular}

* Significant with $\alpha<0.05$.

b. Metropolitan area counties (above the diagonal; $N=1088$ ) and non-metropolitan area counties (below the diagonal; $N=2021$ ). 


\begin{tabular}{|c|c|c|c|}
\hline & (1) & (2) (3) & $\begin{array}{lll}(4) & (5) & (6)\end{array}$ \\
\hline (1) Logistics employment & & $0.904^{*} 0.392^{*}$ & $0.401^{*} 0.447^{*} 0.347^{*} 0.540^{*} 0.413^{*}$ \\
\hline (2) Population & $0.565^{*}$ & $0.491^{*}$ & $0.487^{*} 0.471^{*} 0.299^{*} 0.621^{*} 0.385^{*}$ \\
\hline (3) Population in adjacent counties & $0.161^{*}$ & $0.388^{*}$ & $0.537^{\star} 0.488^{\star} 0.265^{\star} 0.392^{\star} 0.369^{\star}$ \\
\hline (4) $A_{g}$ (road:distribution) & $0.360^{*}$ & $0.526^{*} 0.347^{*}$ & $0.806^{*} 0.476^{*} 0.640^{*} 0.607^{*}$ \\
\hline (5) $A_{g}$ (road:manufacturing) & $0.337^{*}$ & $0.447^{*} 0.263^{*}$ & $0.883^{*} \backslash 0.447^{*} 0.446^{*} 0.679^{*}$ \\
\hline (6) $A_{g}($ air $)$ & $0.096^{*}$ & $0.079 * 0.030$ & $0.363^{*} 0.450^{*}$ \\
\hline (7) $A_{g}$ (maritime) & $0.086^{*}$ & $0.202^{*} 0.166^{*}$ & $0.320^{*} 0.144^{*}-0.027 \backslash 0.297^{*}$ \\
\hline (8) $A_{g}$ (rail) & $0.305^{*}$ & $0.391^{*} 0.227^{*}$ & $0.758^{\star} 0.771^{\star} 0.494^{\star} 0.209^{*}$ \\
\hline
\end{tabular}

* Significant with $\alpha<0.05$.

\subsection{Methodology}

In order to test whether accessibility is a good predictor of logistics employment per county while population is controlled for, a variance based structural equation modeling approach known as Partial Least Squares (PLS) path modeling is used. PLS can be considered as a multivariate extension of ordinary least squares (OLS) regression. In fact, the iterative algorithm performed in PLS generally consists of a series of OLS analyses (Chin, 1998). In contrast, covariance based structural equation modeling (CBSEM, as exemplified by software such as LISREL, AMOS, and EQS) uses maximum likelihood estimation, aiming to maximize the likelihood that the model equals the original correlation matrix. "PLS is based on least squares estimation with the primary objective being to maximize the explanation of variance in a structural equation model's dependent constructs. ... In contrast, the primary measures used in CBSEM are overall goodness-of-fit measures that assess how well the hypothesized model fits the observed data. The model estimation is theory-oriented and emphasizes the confirmatory, rather than exploratory, analysis" (Henseler et al., 2009, p. 311). Hence, PLS is better suited if the primary research objective is the maximization of explained variance in the endogenous constructs (i.e., prediction) or identification of relationships between them (e.g., in early stages of research development) instead of achieving model fit. CBSEM should be the method of choice when the focus lies on confirming theoretically assumed relationships (Reinartz et al., 2009). CBSEM requires a relatively high level of a priori theoretical specification, while PLS offers a more flexible interplay between theory and data (Fornell et al., 1990). As our goal is to determine whether there is a relationship between freight accessibility and logistics employment, while population is controlled for, we will use a PLS model. Our focus is on the explanation of the variance in logistics employment per county by the differences in accessibility and population.

PLS does not make assumptions about the underlying distributions (Fornell and Bookstein, 1982; Chin, 1998; Hair et al. 2011), while CBSEM approaches assume multivariate normality and independence between observations. Hence, PLS is a less demanding method when it comes to the measurement level of the variables, sample sizes, and distributional assumptions (Chin, 1998).

CBSEM generally lacks the ability to estimate research models with formative constructs, whereas the presence of formative constructs does not preclude the use of CBSEM (Peng and Lai, 2012). Applying CBSEM to research models with formative constructs often results in unidentified models (Jarvis et al., 2003). This is because using formative indicators in CBSEM implies zero covariance among indicators. Identification is not a problem for PLS models, as the algorithms performed in PLS analyses consist of a series of OLS analyses (Chin, 1998). Hence, PLS can best be used when formative indicators are present in the research model (Diamantopoulos and Winklhofer, 2001). Formative measurement models can best be used when the items describe and define the construct, while reflective measurement models can best be used when the opposite is the case (Petter et al., 2007). To measure freight accessibility per US county, we use formative measures that 
take into account all modes of transport, consistent with the decision rules by Jarvis et al. (2003). We distinguish between intercontinental freight accessibility and continental freight accessibility. While (rail)roads are mainly used to travel within the US (or to adjacent countries, like Canada), (air)ports are also used to travel overseas. Hence, intercontinental and continental accessibility are modeled separately with two constructs. The use of a formative measurement model has methodological implications. The concepts of internal consistency, reliability, and convergent validity are not meaningful if formative indicators are involved (Hair et al. 2011); formative indicators are primarily based on a theoretical rationale.

Compared to ordinary least squares (OLS) regression, PLS has the advantage that it can capture logical flow among the variables of our model. In contrast, single OLS models are not very appropriate to estimate a causal chain of relationships; OLS only analyzes relationships between (multiple) independent variables and one dependent variable. In PLS models, variables can be both dependent on and functioning as explanatory variables for other variables. Therefore, independent and dependent variables are usually referred to as exogenous and endogenous variables, respectively, in PLS models (Chin, 1998). In our analyses, not only the relationship between freight accessibility and logistics employment is relevant, but so are the relationships between population and freight accessibility, and population and logistics employment.

Figure 3 presents the model that is used to test for a relationship between freight accessibility and logistics employment. The model contains six constructs and four interaction effects. Logistics employment, population, and population of adjacent counties are measured with only one variable per construct. Freight accessibility is split up into two constructs, namely intercontinental and continental freight accessibility. $A_{g}$ (road:manufacturing) and $A_{g}$ (rail) define continental freight accessibility, as these modes of transportation are primarily used to travel within the continent. $A_{g}$ (maritime) and $A_{g}($ air) define intercontinental freight accessibility. Intercontinental freight accessibility has a relation with logistics employment via continental freight accessibility, as the development of (rail)roads is also influenced by the locations of (air)ports. Furthermore, $A_{g}$ (road:distribution) was left out of the model, due to multicollinearity with $A_{g}$ (road:manufacturing) and county population. Finally, a metropolitan area county dummy was included in the model, to be able to test for differences between metropolitan and non-metropolitan area counties. This dummy is equal to 1 if the county is a metropolitan area county and 0 if the county is a non-metropolitan area county. The metropolitan area county construct influences the other constructs directly and acts as a moderator variable that influences the relationships between the other variables, as we expect the relationships between the other constructs to be different in metropolitan and non-metropolitan area counties. 


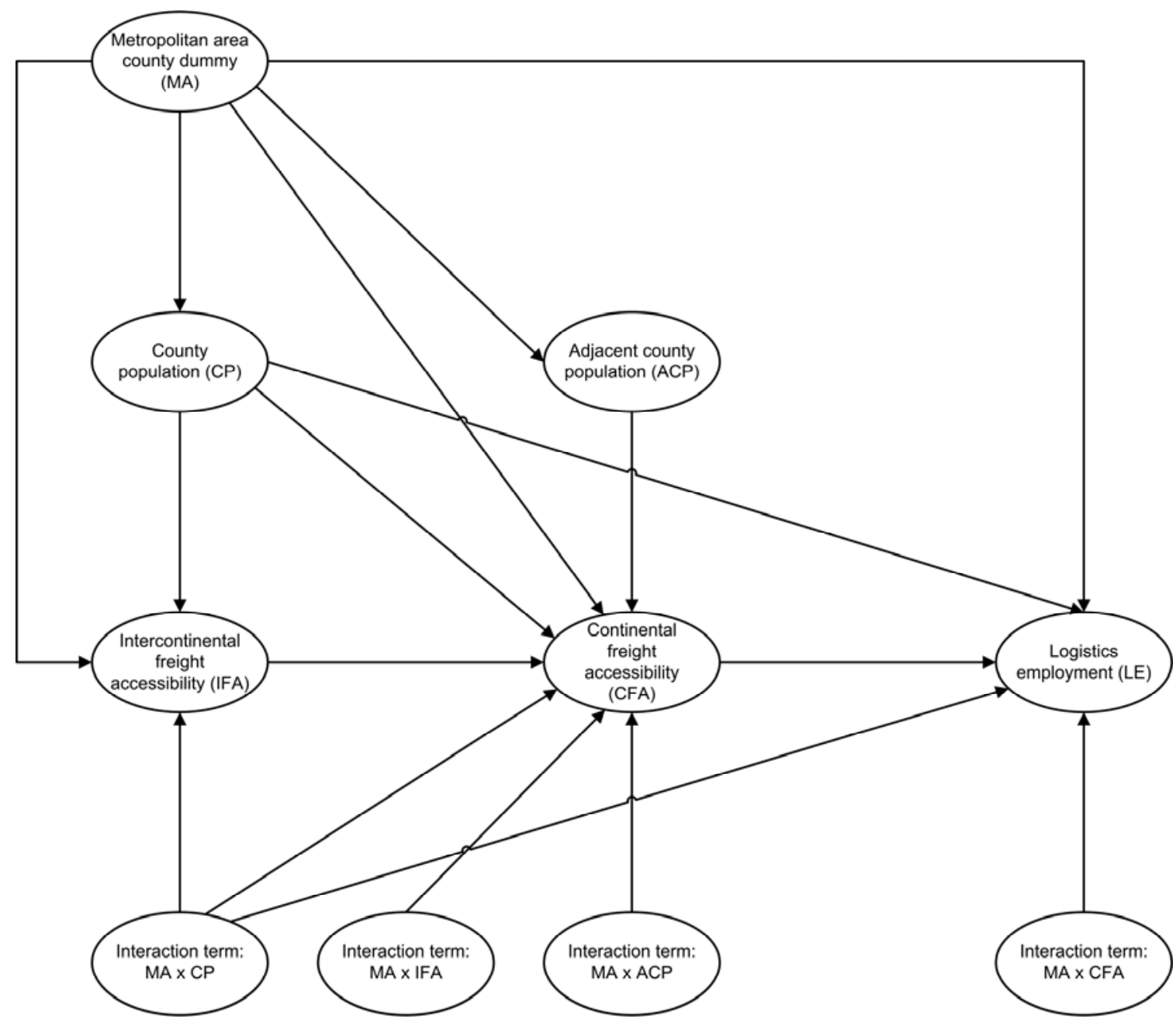

Figure 3: Measurement and structural model with gravity-based accessibility measures.

\subsection{Results}

All parameters within the model were estimated using smartPLS (Ringle et al. 2005). As we want to test a formative measurement model with moderating effects, a two-stage approach has to be used (Henseler and Chin, 2010). In the first stage, the PLS path model without moderating effects is run to obtain estimates for the construct scores. In the second stage, the interaction terms are built up as the products of the construct scores of the exogenous variables and the moderator variable. Table 3 shows the item weights of the accessibility measures on the accessibility constructs obtained from the first stage. Figure 4 shows the model with interaction effects as tested in the second stage. The figure shows standardized coefficients based on a path weighting scheme. In addition, t-statistics are shown resulting from bootstrapping to assess the significance of the coefficients. Consistent with Hair et al. (2011), the number of bootstrap samples was chosen equal to 5000 and the number of cases equal to the number of observations: 3109 counties. To indicate that the coefficients are significantly different from 0 , t-statistics should be higher than 1.96, based on a two-sided test and a significance level of 0.05. For clarification, the insignificant relationships are presented with dashed lines in Figure 4. 
Table 3: Item weights of the gravity-based accessibility measures on the accessibility constructs.

\begin{tabular}{|l|c|c|c|c|}
\hline & \multicolumn{2}{|c|}{ Continental freight accessibility } & \multicolumn{2}{c|}{$\begin{array}{c}\text { Intercontinental freight } \\
\text { accessibility }\end{array}$} \\
\hline & Item weight & T statistic & Item weight & T statistic \\
\hline $\mathrm{A}_{g}$ (road:manufacturing) & 0.631 & 5.308 & & \\
\hline $\mathrm{A}_{g}$ (rail) & 0.433 & 3.517 & & \\
\hline $\mathrm{A}_{g}$ (maritime) & & & 0.760 & 8.347 \\
\hline $\mathrm{A}_{g}$ (air) & & & 0.443 & 3.911 \\
\hline
\end{tabular}

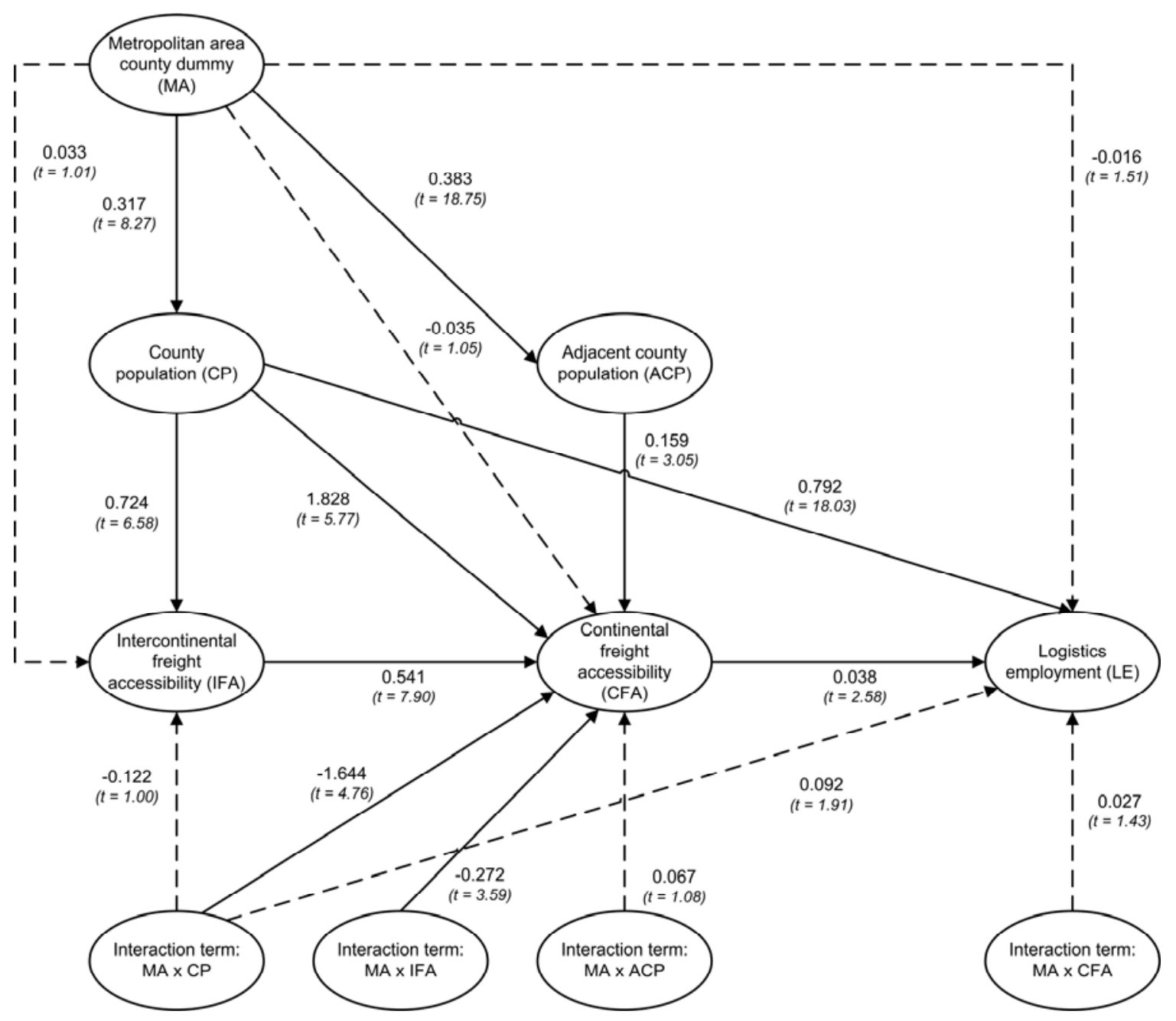

Figure 4: Model with gravity-based accessibility measures.

As can be seen in Figure 4, both the relationships between continental freight accessibility and logistics employment and the relationship between intercontinental and continental freight accessibility are significant. Hence, freight accessibility explains part of the variation in the logistics employment per county. The model that includes the direct relation between intercontinental freight accessibility and logistics employment was also analyzed, but the extra relation turned out not to be significant.

The explanatory power of the model is measured with the adjusted R-square of logistics employment, which is equal to 0.829 . This relatively high number is primarily determined by the relation between 
population and logistics employment. All hypothesized relationships between (adjacent) county population and on the one hand freight accessibility and on the other hand logistics employment are also significant. County population is the most important construct for explaining the variation in logistics employment per county; the standardized coefficient of the relationship between population and logistics employment is equal to 0.792 , while the coefficient between freight accessibility and logistics employment is only 0.038 . Hence, the PLS model shows that it is important to control for the population size per county when analyzing the relationship between accessibility and logistics employment. Although there still is a significant relationship between freight accessibility and logistics employment, this relationship turns out to be much weaker than would have been expected based on the bivariate correlation coefficients shown in Section 5.1. Adjacent county population only has an effect on continental freight accessibility. We also tested for an effect on logistics employment, but since this was not significant, it was excluded from the models for the sake of simplicity.

The metropolitan area county dummy only influences (adjacent) county population directly. Two of the interaction effects shown in Figure 4 turn out to be significant: the metropolitan area county dummy has a significant effect on the relationships between intercontinental and continental freight accessibility and between county population and continental freight accessibility. Figure 5 visualizes these interaction effects based on standardized coefficients and constructs. Both relationships, but especially the latter one, are stronger in non-metropolitan area counties than in metropolitan area counties. A possible explanation might be the facilitator role of infrastructure (Chi, 2010, 2012). More population or an extra (air)port in a non-metropolitan area county may lead to additional (road) infrastructure, while in most metropolitan area counties the dense grid of highways may either reduce the need for additional infrastructure or a smaller effect of such infrastructure on accessibility. Further research to further analyze the relationships between population and accessibility in metropolitan and non-metropolitan areas is warranted.

The results based on gravity-based measures were compared to the results with the density-based measures defined by Bowen (2008). Details are presented in Appendix A. The analysis shows that unlike the gravity-based measures, using the density-based measures results in no significant relation between freight accessibility and logistics employment, while bivariate correlations between these variables are all highly significant. Hence, bivariate correlations serve as a good starting point of most analyses, but have to be interpreted carefully. High bivariate correlations between more than two variables can result in conclusions based on spurious relationships. Our analysis suggests that the high bivariate correlation between freight accessibility and warehouse establishments found by Bowen (2008) is at least partially spurious. 
Figure 5: Interaction effects based on standardized coefficients and constructs.

a) Moderating effect of the metropolitan area county dummy on the relationship between intercontinental and continental freight accessibility.

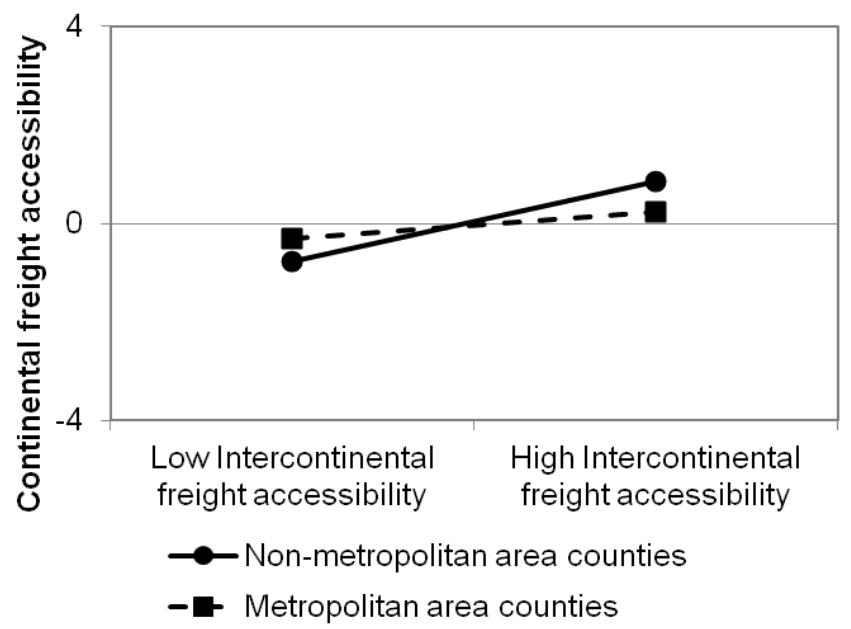

b) Moderating effect of the metropolitan area county dummy on the relationship between county population and continental freight accessibility.

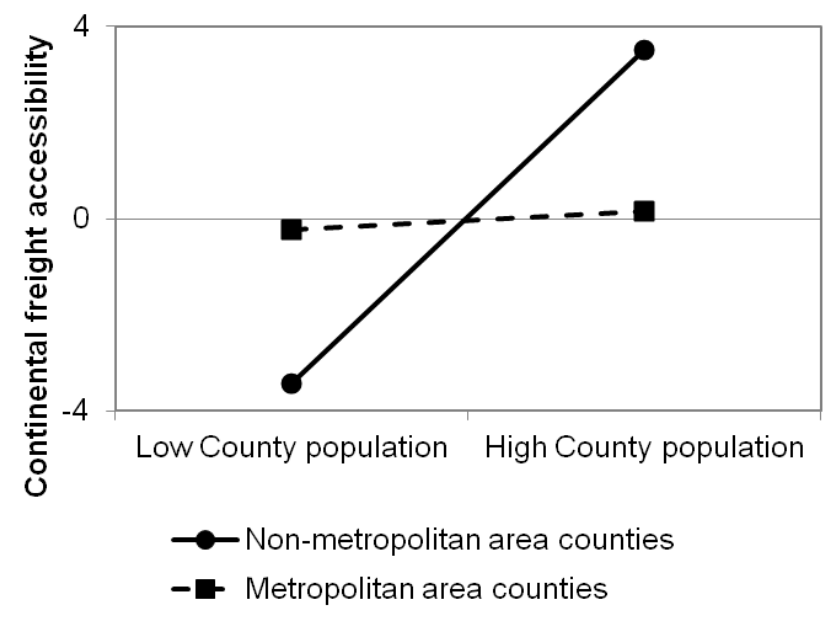

\section{Conclusion}

This paper analyzed the relationship between freight accessibility and logistics employment. We developed a freight accessibility measure that is particularly relevant for logistics companies. Traditionally, accessibility is measured from a passenger perspective, as most of the traffic is passenger related. However, anecdotal evidence suggests that logistics companies are attracted to highly accessible locations (Sheffi, 2012). To be able to measure this relationship, a freight accessibility measure was developed. This measure is based on a gravity model and considers four different modes of transportation: road, air, maritime, and rail. A correlation analysis on a county level in the US suggests that there is a relationship between freight accessibility and logistics employment. However, county population also has a high correlation with both freight accessibility and logistics employment. To test whether the bivariate relationship between freight accessibility and logistics employment is not spurious, a Partial Least Squares model was used. Results show that there is a relationship between freight accessibility and logistics employment on a county level in the US, even after controlling for the effect of county population: better accessible counties have more logistics 
employment. Population, though, is the most important variable in explaining differences in logistics employment levels per county

This paper makes three contributions to the existing literature. First, an accessibility measure was developed that is especially relevant from a freight transport perspective, while existing measures primarily focus on accessibility from a passenger transport perspective. Second, results from the Partial Least Squares model relating freight accessibility to logistics employment, controlling for the effect of the county population, show that highly accessible counties attract more logistics employment than other non-metropolitan counties. Third, the paper showed that for analyzing relationships between freight accessibility and logistics employment it is important to control for the effect of population differences. As both accessibility and logistics employment have a relationship with population, a bivariate analysis might result in a conclusion based on a spurious relationship. Although we did find a significant relationship between freight accessibility and logistics employment, after controlling for population size, the strength of the relationship turns out to be much lower than would have been concluded based on the bivariate analysis only. The finding that analyzing spatial relationships between accessibility and employment with bivariate analyses is not sufficient is in line with previous research by Tomas et al. (2003), Páez (2004), and Ribeiro et al. (2010), who also provide examples of studies where accessibility was either weak or not a significant factor in explaining economic or population distribution/changes.

Some political implications could be derived from this research. First, logistics clusters are getting an increasing amount of attention in policy making, as these have several advantages for logistics firms as well as society as a whole (Sheffi, 2012). This research shows that accessibility is an important determinant of the attractiveness of counties for logistics activities and hence, should be taken into account in government policies to attract logistics firms. Second, although freight accessibility turns out to have an effect on the logistics employment per county, policy makers should be aware of the strong relationship between both these constructs and the county population. Without taking this into account, results look different than they actually are.

In this paper, we defined accessibility based on four different modes of transportation, namely road, rail, maritime, and air transportation. From a policy perspective, an interesting follow-up question on this analysis would be whether there is a difference in the use of more sustainable transport modes (rail and maritime) in counties with a higher accessibility to these modes. While in this paper we were interested in the combined level of accessibility, policy makers may be more interested in the attractiveness of counties based on "sustainable accessibility", i.e. whether counties with a good rail and/or maritime accessibility attract (additional) logistics employment. In such an analysis, it is important to measure whether the logistics companies located in these counties also actually use these modes of transport. Hence, additional data are needed for such an analysis. In addition, the difference between the relationship between population and accessibility in metropolitan and nonmetropolitan area counties deserves further attention in future research.

\section{Appendix A. Density-based (rail)road accessibility}

Bowen (2008) defined density-based accessibility measures to measure (rail)road accessibility. These measures divide the kilometers of (rail)road per county by the county's area $\left(r_{i} / s_{i}\right)$. Standardizing these measures results in the following measure $A_{d, i}$ :

$$
A_{d, i}=\frac{a_{d, i}}{\frac{1}{l} \cdot \sum_{j \in l} a_{d, i}} \text { with } a_{d, i}=\frac{r_{i}}{s_{i} / s_{\text {med }}}
$$

with: 
$A_{d, i}=$ Accessibility (density-based) of county $i$,

$r_{i}=$ Length of all relevant (rail)roads in county $i$ (in kilometers),

$s_{i}=$ Area of county $i$ (in square kilometers),

$s_{\text {med }}=$ Median of all $s_{i}$ (in square kilometers).

To measure road and rail accessibility in this appendix, $r_{i}$ is equal to the sum of the length of the major roads part of the US principal arterial network (US Department of Transportation, 2011a), and major railroads, owned by the Class I freight railroad companies in the US, respectively.

Table A1 presents the correlations between logistics employment, population, and the density-based accessibility measures. Generally, the correlation of the gravity-based measures (see Table 1) and logistics employment is higher than the correlation of the density-based measures (see Table A1) and logistics employment. For example, for road transport, the correlation between the gravity-based measure $A_{g}$ (road:manufacturing) and logistics employment is 0.451 , while the correlation between the density-based measure $A_{d}($ road) and logistics employment is only 0.350 .

Table A1: Pearson correlation coefficients.

a. All counties $(N=3109)$.

\begin{tabular}{|c|c|c|c|c|c|}
\hline & $\begin{array}{l}\text { Logistics } \\
\text { employment }\end{array}$ & Population & $\begin{array}{c}\text { Population in } \\
\text { adjacent } \\
\text { counties }\end{array}$ & $A_{D}($ road $)$ & $A_{D}($ rail $)$ \\
\hline Logistics employment & & $0.909^{*}$ & $0.434^{*}$ & $0.350^{*}$ & $0.267^{*}$ \\
\hline Population & & & $0.530^{*}$ & $0.414^{*}$ & $0.234^{*}$ \\
\hline Population in adjacent counties & & & & $0.374^{*}$ & $0.185^{*}$ \\
\hline$A_{d}($ road $)$ & & & & & $0.588^{*}$ \\
\hline$A_{d}($ rail $)$ & & & & & \\
\hline
\end{tabular}

* Significant with $\alpha<0.05$.

b. Metropolitan area counties (above the diagonal; $N=1088$ ) and non-metropolitan area counties (below the diagonal; $N=2021$ ).

\begin{tabular}{|c|c|c|c|c|c|}
\hline & $\begin{array}{l}\text { Logistics } \\
\text { employment }\end{array}$ & Population & $\begin{array}{l}\text { Population in } \\
\text { adjacent } \\
\text { counties }\end{array}$ & $A_{D}($ road $)$ & $A_{D}($ rail) \\
\hline Logistics employment & ${ }^{2}$ & $0.904^{*}$ & $0.392^{*}$ & $0.294^{*}$ & $0.241^{*}$ \\
\hline Population & $0.565^{*}$ & & $0.491^{*}$ & $0.356^{*}$ & $0.188^{*}$ \\
\hline Population in adjacent counties & $0.161^{*}$ & $0.388^{*}$ & & $0.313^{*}$ & $0.119^{*}$ \\
\hline$A_{d}($ road $)$ & $0.191^{*}$ & $0.271^{*}$ & $0.059^{*}$ & & $0.577^{*}$ \\
\hline$A_{d}($ rail $)$ & $0.126^{*}$ & $0.120^{*}$ & -0.008 & $0.588^{*}$ & \\
\hline
\end{tabular}

${ }^{*}$ Significant with $\alpha<0.05$.

The PLS analysis was also conducted with the density-based measures; see Figure A1 and Table A2. In this model, $A_{g}$ (road:manufacturing) and $A_{g}$ (rail) are replaced by $A_{d}\left(\right.$ road) and $A_{d}$ (rail). $A_{g}$ (air) and $A_{g}$ (maritime) are still included in the model, as Bowen (2008) used simplified gravity-based measures and no density-based measures for these transport modes. In general, the PLS model with the density-based accessibility measures shows many similarities with the PLS models with the gravitybased measures. The most important difference is that with density-based measures, there is no relation between freight accessibility and logistics employment. Hence, although the positive correlation between the density-based accessibility measures and logistics employment suggest that 
there is a relationship between these variables per county, this turns out to be spurious, as it can be fully explained by the relations between these variables and the county population.

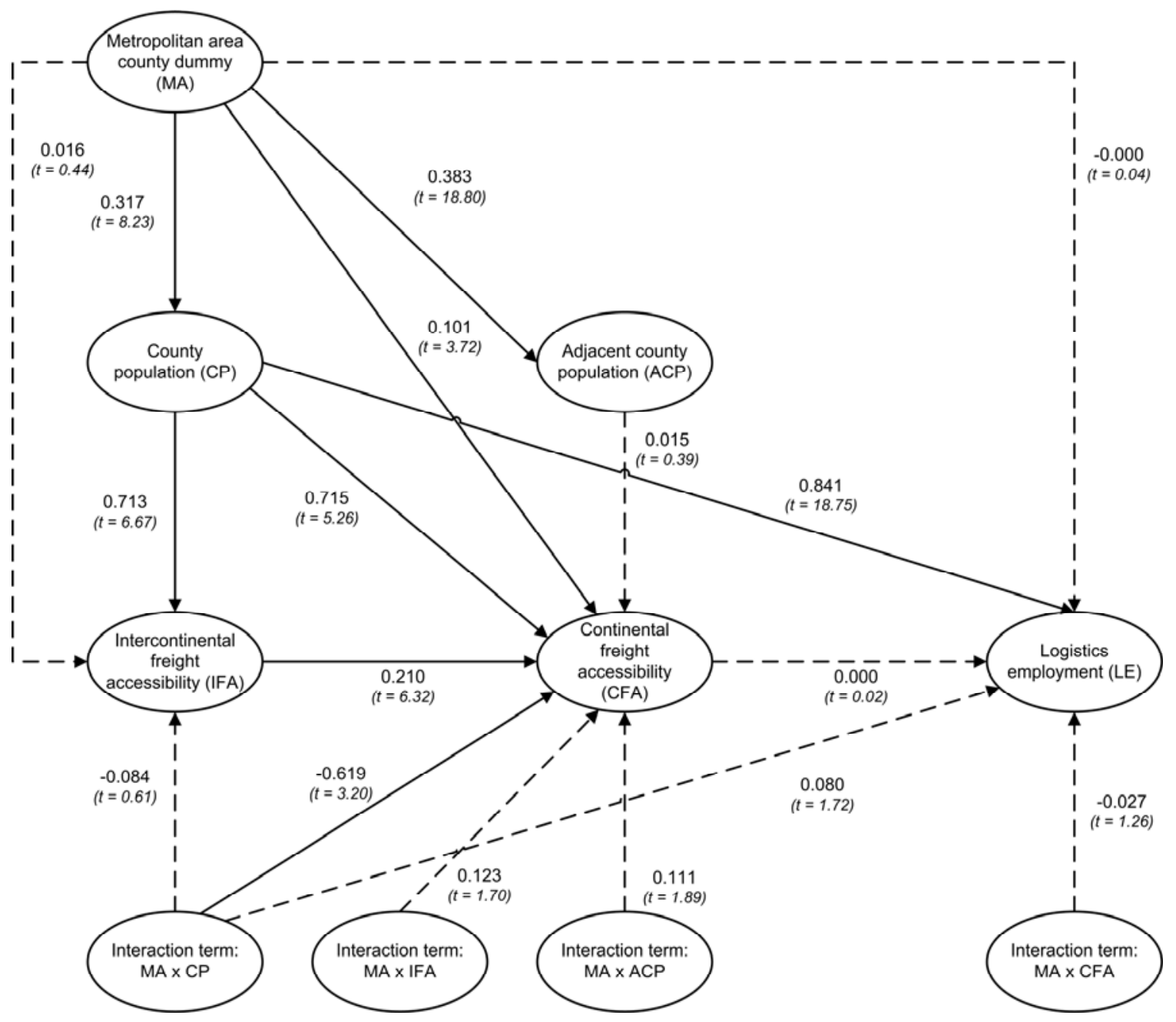

Figure A1: Model with density-based accessibility measures.

Table A2: Item weights of the density-based accessibility measures on the accessibility constructs.

\begin{tabular}{|l|c|c|c|c|}
\hline & \multicolumn{2}{|c|}{$\begin{array}{c}\text { Intercontinental freight } \\
\text { accessibility }\end{array}$} \\
\hline & Item weight & T statistic & Item weight & T statistic \\
\hline $\mathrm{A}_{d}($ road $)$ & 0.972 & 13.493 & & \\
\hline $\mathrm{A}_{d}$ (rail) & 0.046 & 0.402 & & \\
\hline $\mathrm{A}_{g}$ (maritime) & & & 0.893 & 24.354 \\
\hline $\mathrm{A}_{g}$ (air) & & & 0.241 & 3.623 \\
\hline
\end{tabular}

\section{Appendix B. Industry codes of the logistics sector in the US}

The North American Industry Classification System (NAICS) is the standard used by Federal statistical agencies in the US to classify business establishments for the purpose of collecting, analyzing, and publishing statistical data (US Census 2012a). Table B1 presents the NAICS codes used to identify the logistics sector in the US. 
Table B1: NAICS codes used to define the logistics sector

\begin{tabular}{|l|l|c|}
\hline NAICS & Description & $\begin{array}{c}\% \text { of logistics } \\
\text { employment }\end{array}$ \\
\hline $481112 ; 481212 ; 481219$ & Air freight transportation & $0.7 \%$ \\
\hline $483111 ; 483113 ; 483211$ & Water freight transportation & $1.6 \%$ \\
\hline $4841 ; 48422 ; 48423$ & Freight trucking & $42.2 \%$ \\
\hline $\begin{array}{l}488119 ; 48819 ; 4882 ; 4883 ; 4884 ; \\
4885 ; 4889\end{array}$ & $\begin{array}{l}\text { Supporting activities for freight } \\
\text { transportation }\end{array}$ & $18.7 \%$ \\
\hline 492 & Couriers & $17.4 \%$ \\
\hline $49311 ; 49319$ & Warehousing and storage & $19.4 \%$ \\
\hline Total & & $100.0 \%$ \\
\hline
\end{tabular}

\section{References}

Allen, W.B., Liu, D., and Singer, S. (1993) Accessibility measures of U.S. metropolitan counties. Transportation Research Part B, 27(6), 439-449.

Banister, D., and Berechman, J. (2000) Transport investment and economic development. Spon Press, London.

Bellman, R.E. and Zadeh, L.A. (1970) Decision-making in a fuzzy environment. Management Science, 17 (4), 141-164.

Ben-Akiva, M. and Lerman, S.R. (1985) Discrete choice analysis, Theory and application to travel demand. The MIT Press, Cambridge, MA.

Berechman, J. (1994) Urban and regional economic impacts of transportation investment: a critical assessment and proposed methodology. Transportation Research Part A, 28(4), 351-362.

Berechmen, J., Ozmen, D., and Ozbay, K. (2006) Empirical analysis of transportation investment and economic development at stae, county and municipality levels. Transportation, 33, 537-551.

Berechman, J. and Paaswell, R. (2001) Accessibility improvements and local employment: An empirical analysis. Journal of Transportation Statistics, 4(2/3), 49-66

Bowen, J. (2008) Moving places: the geography of warehousing in the US. Journal of Transport Geography, 16, 379-387.

Chi, G. (2010) The impacts of highway expansion on population change: an integrated spatial approach, Rural Sociology, 75(1), 58-89.

Chi, G. (2012) The impacts of transport accessibility on population change across rural, suburban and urban areas: A case study of Wisconsin at sub-county levels. Urban Studies, 49, 2711-2731.

Chin, W.W. (1998) The partial least squares approach to structural equation modeling. Modern Methods for Business Research ed G.A. Marcoulides. Lawrence Erlbaum Associates, New Jersey.

De Graaff, T., Van Oort, F.G., and Florax, R.J.G.M. (2012a) Regional population-employment dynamics across different sectors of the economy. Journal of Regional Science, 52(1), 60-84

De Graaff, T., Van Oort, F.G., and Florax, R.J.G.M. (2012b) Sectoral heterogeneity accessibility and population-employment dynamics in Dutch cities. Journal of Transport Geography, 25, 115-127

Diamantopoulos, A. and Winklhofer, H.M. (2001) Index construction with formative indicators: an alternative to scale development, Journal of Marketing Research, 38, 269-277.

Du, H. and Mulley, C. (2007) The Short-Term Land Value Impacts Of Urban Rail Transit: Quantitative Evidence from Sunderland, UK. Land Use Policy, 24(1), 223-233.

El-Geneidy, A. and Levinson, D. (2006) Access to destinations: development of accessibility measures. Report \#1 in the series Access to Destinations Study. Minnesota Department of Transportation, Research Service Section, St. Paul, MN. 
Fan, X., Tian, S., Shen, T., and Zhang, J. (2012) The accessibility assessment of national transportation network and analysis of spatial pattern. Future Control and Automation ed W. Deng, pp. 415-423. Springer-Verlag, Berlin.

Fornell, C., and Bookstein, F.L. (1982) Two structural equation models: LISREL and PLS applied to consumer exit-voice theory. Journal of Marketing, 19, 440-452.

Fornell, C., Lorange, P., and Roos, J. (1990) The cooperative venture formation process: a latent variable structural modeling approach, Management Science, 36(10), 1246-1255.

Geurs, K.T. and Van Wee, B. (2004) Accessibility evaluation of land-use and transport strategies: review and research directions. Journal of Transport Geography, 12, 127-140.

Hair, J.F., Ringle, C.M., and Sarstedt, M. (2011) PLS-SEM: Indeed a Silver Bullet. Journal of Marketing Theory and Practice, 19(2), 139-151.

Handy, S. and Niemeier, D. (1997) Measuring accessibility: an exploration of issues and alternatives. Environment and Planning A, 29, 1175-1194.

Hansen, W. (1959) How accessibility shapes land use. Journal of American Institute of Planners, 25, 73-76.

Henseler, J. and Chin, W.W. (2010) A comparison of approaches for the analysis of interaction effects between latent variables using Partial Least Squares path modeling, Structural Equation Modeling, 17, 82-109.

Henseler, J., Ringle, C.M., and Sinkovics, R.R. (2009) The use of partial least squares path modeling in international marketing, Advances in International Marketing, 20, 277-319.

Hesse, M. (2008) The city as a terminal: The urban context of logistics and freight transport. Ashgate Publishing Company, Burlington, VT.

Hong, J. (2007) Transport and the location of foreign logistics firms: the Chinese experience. Transportation research Part A, 41, 597-609.

Ingram, D. (1971) The concept of accessibility: a search for an operational form. Regional Studies, 5, 101-107.

Jarvis, C.B., MacKenzie, S.B., and Podsakoff, P.M. (2003) A critical review of construct indicators and measurement model misspecification in marketing and consumer research. Journal of Consumer Research, 30(2),199-218.

Jiwattanakulpaisarn, P., Noland, R.P., and Graham, D.J. (2010) Causal linkages between highways and sector-level employment. Transportation Research Part A, 44, 265-280

Koenig, J. (1980) Indicators of urban accessibility: theory and application. Transportation, 9, 145-172.

Leitham, S., McQuaid, R.W., and Nelson, J.D. (2000) The influence of transport on industrial location choice: a stated preference experiment. Transportation Research Part A, 34, 515-535.

Levenberg, K. (1944) A method for the solution of certain non-linear problems in least squares. Quarterly of Applied Mathematics, 2, 164-168.

Lim, H. and Thil, J.-C. (2008) Intermodal freight transportation and regional accessibility in the United States. Environment and Planning A, 40, 2006-2025.

Limão, N. and Venables, A. (2001) Infrastructure, geographical disadvantages, transport costs, and trade. The World Bank Economic Review, 15(3), 451-479.

Marquardt, D.W. (1963) An algorithm of least-squares estimations of non-linear parameters. SIAM Journal of Applied Mathematics, 11(2), 431-441.

Matisziw, T.C. and Grubesic, T.H. (2010) Evaluating locational accessibility to the US air transportation system. Transportation Research Part A, 44, 710-722.

Miller, H.J. (1999) Measuring space-time accessibility benefits within transportatio networks: basic theory and computational procedures. Geographical Analysis, 31 (1), 1-26.

Morris, J., Dumble, P., and Wigan, M. (1978) Accessibility indicators for transport planning. Transportation Research Part A, 13A, 91-109.

Neutens, T., Schwanen, T., Witlox, F., and De Maeyer, P. (2010) Equity of urban servic delivery: a comparison of different accessibility measures. Environment and Planning A, 42, 1613-1635. 
Ozbay, K., Ozmen, D., and Berechman, J. (2006) Modeling and Analysis of the Link between Accessibility and Employment Growth. Journal of Transportation Engineering, 132(5), 385-393.

Páez, A. (2004) Network accessibility and the spatial distribution of economic activity in Eastern Asia. Urban Studies, 11, 2211-2230.

Páez, A., Scott, D.M., and Morency, C. (2012) Measuring accessibility: positive and normative implementations of various accessibility indicators. Journal of Transport Geography, 25, 141153

Peng, D.X. and Lai, F. (2012) Using partial least squares in operations management research: a practical guideline and summary of past research, Journal of Operations Management, 30, 467480.

Petter, S., Straub, D., and Rai, A. (2007) Specifying formative constructs in information systems research. MIS Quarterly, 31(4), 623-656.

Porter, M.E. and Rivkin, J.W. (2012) Choosing the United States. Harvard Business Review, March 2012

Reinartz, W., Haenlein, M., and Henseler, J. (2009) An empirical comparison of the efficacy of covariance-based and variance-based SEM, International Journal of Research in Marketing, 26, 332-344.

Ribeiro, A., Antunes, A.P., and Páez, A. (2010), Road accessibility and cohesion in lagging regions: empirical evidence from Portugal based on spatial econometric models. Journal of Transport Geography, 18, 125-132.

Rietveld, P. (1994) Spatial economic impacts of transport infrastructure supply. Transportation Research Part A, 28(4), 329-341.

Ringle, C.M., Wende, S., and Will, A. (2005) SmartPLS. www.smartpls.de.

Rivera, L. and Sheffi, Y. (2012) Logistics clusters in the US. MIT CTL Research Paper CTL/1-A-12.

Sheffi, Y. (2012) Logistics Clusters: Delivering value and driving growth. MIT Press, Cambridge, MA.

Song, Y., Lee, K., Anderson, W.P., and Lakshmanan, T.R. (2012) Industrial agglomeration and transport accessibility in metropolitan Seoul. Journal of Geographical Systems, 14, 299-318

Taniguchi, E., Noritaki, M., Yamada, T., and Izumitani, T. (1999) Optimal size and location planning of public logistics terminals. Transportation Research Part E, 35, 207-222

Thill, J.-C. and Lim, H. (2010) Intermodal containerized shipping in foreign trade and regional accessibility advantages. Journal of Transport Geography, 18, 530-547.

Thomas, I., Hermia, J.P., Vanelslander, T., and Verhetsel, A. (2003) Accessibility to freight transport networks in Belgium: a geographical approach. Tijdschrift voor Economische en Sociale Geografie, 94, 424-438.

Thompson, R., and Taniguchi, E. (2001) City logistics and freight transport. The Handbook of Logistics and Supply-Chain Management, Handbooks in Transport \#2 eds A.M. Brewer, K.J. Button, and D.A. Hensher, pp. 393-404. Pergamon/Elsevier, London.

US Army Corps of Engineers (2010) Waterborne Commerce Statistics Center, Navigation Data Center, http://www.ndc.iwr.usace.army.mil/, accessed December 2012.

US Census (2002) Economic Census, Vehicle Inventory and Use Survey,www.census.gov, accessed December 2012.

US Census (2007a) County Business Patterns,www.census.gov, accessed December 2012.

US Census (2007b) Population Estimates,www.census.gov, accessed December 2012.

U.S. Census (2012a) Introduction to NAICS, www.census.gov/eos/www/naics/, accessed December 2012.

US Census (2012b) Metropolitan and Micropolitan Areas Main, www.census.gov/population/metro/, accessed December 2012.

US Department of Transportation (2010) Freight Facts and Figures, http://ops.fhwa.dot.gov/freight/freight analysis/nat freight stats/docs/10factsfigures/index.htm, accessed December 2012. 
US Department of Transportation (2011a) FHWA Functional Classification Guidelines, http://www.fhwa.dot.gov/planning/fcsec2 1.htm, accessed December 2012.

US Department of Transportation (2011b) Highway Statistics 2011, Section 5: Highway travel, Vehicle miles of travel and related data, by highway category and vehicle type, http://www.fhwa.dot.gov/policyinformation/statistics/2011, accessed April 2013.

US Department of Transportation (2011c) National Transportation Atlas Database, http://www.rita.dot.gov/bts/sites/rita.dot.gov.bts/files/publications/national transportation atlas database/2011/index.html, accessed December 2012.

Van den Heuvel, F.P., De Langen, P.W., Van Donselaar, K.H., and Fransoo, J.C. (2013) Spatial concentration and location dynamics in logistics: the case of a Dutch province. Journal of Transport Geography, 28, 39-48

Weisbrod, R.M., Reed, J.S., and Neuwirth, G.E. (1993) Airport area economic development model. Paper presented at the PTRC International Transport Conference, Manchester, England.

Zhenbo, W., Jiangang, X., Chuanglin, F., Lu, X., and Yi, L. (2011) The study on county accessibility in China: Characteristics and effects on population agglomeration. Journal of Geographical Sciences, 21(1), 18-34. 